\title{
Yttrium iron garnet thick film inclusion for enhanced microstrip patch antenna performance
}

\begin{abstract}
The present investigation deals with the fabrication of silver $(\mathrm{Ag})$ patch antenna with yttrium iron garnet (YIG) thick film layer inclusion as substrate overlay to enhance its performance. In this paper, YIG nanopowder was mixed with organic vehicle which consists of linseed oil, $\mathrm{m}$-xylene and Ü-terpineol with powder ratio of $30 \mathrm{wt} \%$. Then the mix was stirred at 150rpm for 3 hours at $40^{\circ} \mathrm{C}$ in order to obtain homogenous paste, followed by printing it onto FR4 substrate using the screen printing technique to form the YIG thick film layer before dried at $200^{\circ} \mathrm{C}$. A basic square shape patch antenna by using silver paste was printed onto the YIG layer and then compared with another patch antenna which was printed without the YIG layer. The results shown that the antenna with YIG thick film layer has return loss of $19.67 \mathrm{~dB}$, resonant frequency $6.42 \mathrm{GHz}$, bandwidth 3.13 and $\mathrm{Q}$ factor of 2.051 , which is better compared to the antenna without the layer by $138.13 \%, 3.22 \%, 49.76 \%$ and $31.08 \%$ respectively.
\end{abstract}

Keyword: Yttrium iron garnet; Thick film; Microstrip patch antenna; Bandwidth; YIG; Nanopowder 